\title{
Production and global transport of Titan's sand particles
}

\author{
Jason W Barnes ${ }^{1 *}$, Ralph D Lorenz ${ }^{2}$, Jani Radebaugh ${ }^{3}$, Alexander G Hayes ${ }^{4}$, Karl Arnold ${ }^{3}$ \\ and Clayton Chandler ${ }^{3}$
}

*Correspondence:

jwbarnes@uidaho.edu

1 Department of Physics, University

of Idaho, Moscow, Idaho,

83844-0903 USA

Full list of author information is

available at the end of the article

\begin{abstract}
Previous authors have suggested that Titan's individual sand particles form by either sintering or by lithification and erosion. We suggest two new mechanisms for the production of Titan's organic sand particles that would occur within bodies of liquid: flocculation and evaporitic precipitation. Such production mechanisms would suggest discrete sand sources in dry lakebeds. We search for such sources, but find no convincing candidates with the present Cassini Visual and Infrared Mapping Spectrometer coverage. As a result we propose that Titan's equatorial dunes may represent a single, global sand sea with west-to-east transport providing sources and sinks for sand in each interconnected basin. The sand might then be transported around Xanadu by fast-moving Barchan dune chains and/or fluvial transport in transient riverbeds. A river at the Xanadu/Shangri-La border could explain the sharp edge of the sand sea there, much like the Kuiseb River stops the Namib Sand Sea in southwest Africa on Earth. Future missions could use the composition of Titan's sands to constrain the global hydrocarbon cycle.
\end{abstract}

We chose to follow an unconventional format with respect to our choice of section headings compared to more conventional practice because the multifaceted nature of our work did not naturally lend itself to a logical progression within the precribed system. The present format corresponds to the conventional format as following: "Who?" and "What?" correspond to Background, "Where?" and parts of "How?" to Methods, "When?" and portions of "How?" to Results and Discussion, and "Why?" represents the Conclusion. We are of the opinion this format enhances readability of the publication and take full responsibility to any confusion it may cause. Any correspondence in such a situation is asked to be directed to the corresponding author only.

\section{Who?}

Lorenz et al. (2006) [1] discovered dunes on Saturn's moon Titan using Cassini RADAR observations. The dunes are overwhelmingly longitudinal in form. On Earth, longitudinal dunes form in bimodal wind regimes where the two modal wind directions differ by more than $90^{\circ}$. The net transport direction for longitudinal dunes on any planet is along the crest, rather than across the crests as for transverse dunes.

Radebaugh et al. (2008) [2] deduced that Titan's net sand transport direction is westto-east. That result derives from analysis of the patterns of dune deflection around

(C) 2015 Barnes et al. This is an Open Access article distributed under the terms of the Creative Commons Attribution License (http://creativecommons.org/licenses/by/4.0), which permits unrestricted use, distribution, and reproduction in any medium, provided the original work is properly cited. 
topographic obstacles within the sand seas [3]. Although initial global circulation models showed average winds in the opposite direction [4-6], recent models by Tokano (2010) [7] are able to reproduce peak winds (those that transport the greatest flux of particles) in the west-to-east direction. Lucas et al. (2014) [8] showed that peak winds from global circulation models could have generated the observed dune distribution during periodic equinoctial storms.

Lorenz et al. (2006) [1], Radebaugh et al. (2008) [2], Barnes et al. (2008) [9], Neish et al. (2010) [10], and Mastrogiuseppe et al. (2014) [11] measured dune heights. The measured values - 100-150 m [1], 100-200 m [2], 30-70 m [9], 45-180 m [10], and 60-120 m [11] respectively - resemble those of Earth's longitudinal sand dunes in the Namib, Sahara, Arabian, and Taklamakan deserts.

Radebaugh et al. (2008) [2], Barnes et al. (2008) [9], Le Gall et al. (2011 and 2012) [12,13], and Ewing et al. (2015) [14] measured the dune spacings, or the distance between the crests of adjacent longitudinal dunes. Those authors measured the distances to be $1-4 \mathrm{~km}$ [2], $2.1 \mathrm{~km}$ [9], $3 \mathrm{~km}$ [12], and $3 \mathrm{~km}$ [14] respectively. The dune spacing varies with latitude, perhaps resulting from changes in sand supply [13]. Radebaugh (2010) [15] noted the similarity of the heights and spacings to those seen in longitudinal dunefields on Earth, despite Titan's differing gravity, atmospheric density, and composition. Lorenz et al. (2010) [16] attributed the similar length parameters to a common scaling mechanism based in the height of the atmospheric boundary layer, which may be similar between the two worlds $(\sim 3 \mathrm{~km})$.

Ewing et al. (2015) showed that the overall pattern of the dunes' morphology indicates that the dunes are in long-term equilibrium [14]. As large, longitudinal dunes, they likely respond to long-timescale forcing [14]. At the same time, the persistence of sand-free interdunes indicates that the dunes are presently active [9].

McCord et al. (2006 and 2008) [17,18], Soderblom et al. (2007) [19], and Barnes et al. (2007 and 2008) [9,20] used Cassini Visual and Infrared Mapping Spectrometer (VIMS) coverage of the sand seas to show that the sand's spectrum is inconsistent with that of water ice. Microwave radiometery from the RADAR instrument confirms that the dunes' composition cannot be composed mainly of water ice [21]. The dunes have a 'dark brown' appearance in infrared color images (such as those with $\mathrm{R}=5 \mu \mathrm{m}, \mathrm{G}=2 \mu \mathrm{m}, \mathrm{B}=1.3 \mu \mathrm{m}$ [20] or $\mathrm{R}=2 \mu \mathrm{m}, \mathrm{G}=1.6 \mu \mathrm{m}, \mathrm{B}=1.3 \mu \mathrm{m}$ ) [19]) and this dark brown spectral unit correlates strongly with the presence of dune morphologies in RADAR. The spectrum of this area broadly matches with various organics. Clark et al. (2010) [22] saw absorption signatures of benzene in some dune areas, but the signal does not spatially correlate with the dunes.

Lorenz (2013) [23] calculated the theoretical size for particles that would be expected to saltate in Titan surface conditions to be around 300 microns (saltation is the low hopping process by which sand moves, as can be felt on the ankles of a tourist on the beach on a windy day). Median particle diameters for sand on Earth are around 200 microns. Geologists define 'sand' as composed of particles between 0.0625 and 2 millimeters in diameter. Use of the sand nomenclature on Titan then represents this particle size and is not indicative of a composition. The precise particle diameter for the initiation of saltation depends on the cohesion between grains. If that cohesion were higher than for terrestrial particles, for instance, then Titan's sand could be up to 600 microns in size [23]. New wind-tunnel experiments confirm the expectation of Titan's sand in the $\sim$ few hundred microns size range [24]. 
In this work, we investigate the origins and global mobility of the individual sand particles that comprise Titan's dunes. This work is intended as a broad initial foray into sand formation and transport and as such concentrates more on outlining the scope of the problem and future work rather than assigning conclusive mechanisms. First, in the "What" Section we outline the problem of why identification of a sand source is necessary. Then in the next Section, "How", we consider the nuts-and-bolts of how to build 300-micron sand particles, considering both bottom-up and top-down approaches. In Section "Where" we conduct a search for areas that might represent proximal sand source regions using VIMS spectra. We then consider an alternate scenario of long-lived global transport of Titan's sands in Section "When" before discussing the results and concluding in the Section titled "Why".

\section{What?}

On Earth, most (but not all) sand is composed of silica, $\mathrm{SiO}_{2}{ }^{\mathrm{a}}$. The primary source for sand on Earth is the erosion of silica-rich igneous and metamorphic rock - primarily granite and gneiss. Both physical and chemical erosion break down other abundant minerals, such as feldspars and iron-rich minerals. Quartz crystals and silica cobbles, on the other hand, can only be physically abraded to smaller and smaller pieces. Silica therefore is able to resist continued breakdown into pieces smaller than sand through physical strength where feldspar and other minerals get broken down chemically into clays and other finer-grained sediments $[25,26]$.

Those pieces with diameters much greater than 300 microns are too large to be saltated by the wind. A particular advantage of silica for forming dunes on Earth is that once broken into 200-micron-sized particles, silica resists further fracturing. Thus, once mobilized by the wind, the particles can self-organize into very large dune structures without being broken into sizes so small that they can become entrained in the air as dust.

Sand on Earth is produced directly from the composition of the types of rock that form the bulk of the crust. Since water ice forms the bulk of Titan's crust, we expected that Titan's sand would be made of water ice [27,28]. It is not [19-22]. The spectra may instead match organics, although that identification is non-unique.

If the dune sands are made of organics, then it stands to reason then that the ultimate source of those organics is probably the organic haze in Titan's atmosphere (see [29] for how the haze is produced). It has therefore been suggested that maybe the haze particles are the sand and that the sand is continuously 'snowing' out of the atmosphere as the haze settles. That is not the case.

The problem is one of size. The modal diameter of haze particles is around 1 micron (though the sizes may get to $\sim 10$ microns near the surface [30]). The diameter of sand particles was theoretically calculated to be around 300 microns. Thus the mass of a sand particle is greater than the mass of a 1-micron haze particle by a factor of $>10^{7}($ !). Therefore, the mechanism that produces sand particles must produce objects ten million times the size of a haze particle. We investigate some possible mechansims to do this in the next section.

\section{How?}

We group all possible sand formation mechanisms into two categories: bottom-up and top-down (which we illustrate in a cartoon format in Figure 1). A bottom-up approach 


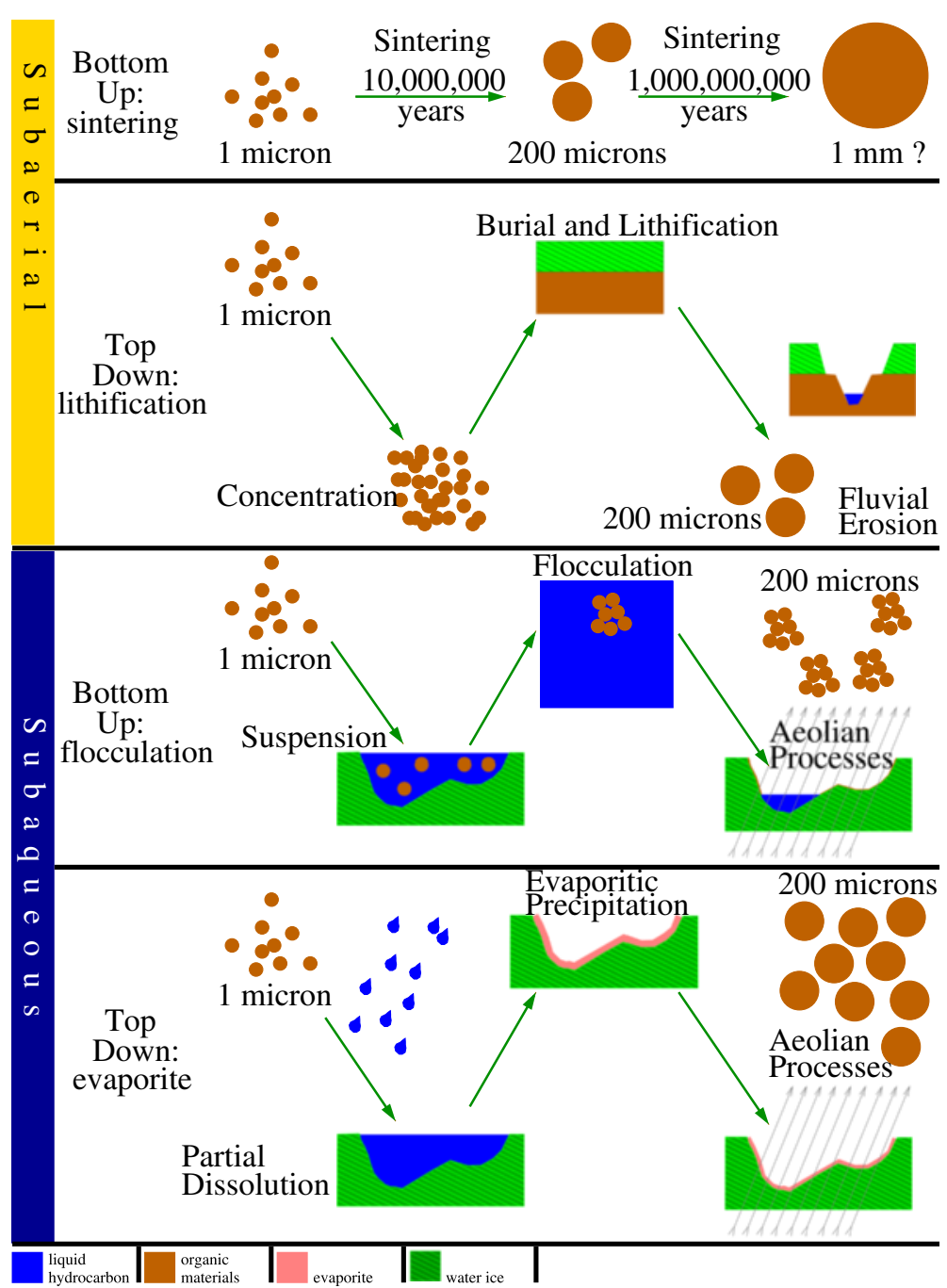

Figure 1 Sand production mechanisms. Four different proposed pathways for the production of 300-micron saltatable organic particles on Titan. In the 'bottom-up' approach, individual haze particles fuse together over time by sintering or flocculation. In the 'top-down' approaches the 1-micron haze particles first form much larger rocks by either lithification or dissolution and precipitation before being broken down into sand-sized particles.

builds sand from smaller particles (presumably haze) by agglomeration. By contrast, a top-down mechanism creates sand by breaking down larger rocks into smaller and smaller pieces until the requisite 300-micron size is reached, similar to how silica sand forms on Earth. We investigate candidate processes in each of these categories in turn.

\section{Bottom-up}

As haze particles fall out onto Titan's surface, they will necessarily pile up on top of one another. Indeed, Soderblom et al. (2007) [19] suggested that the non-ice coating of Titan's Equatorial Bright terrain may represent a haze-based surficial deposit masking the (presumably water-ice) bedrock. With that many haze particles all in the same place, eventually the $10^{7}$ particle threshold will be met. 
In order to represent the sand that forms Titan's dunes, though, the particles need also be durable. Fluffy haze aggregates, even with the right mass, might be expected to easily break apart upon saltation because the end of a saltation jump necessarily requires a high-speed collision with other particles in the dune. So some mechanism to harden the particles would be needed for this bottom-up approach to be viable.

\section{Sintering}

A bottom-up process that has been previously suggested for sand formation is sintering [9]. For solids in the vicinity of their melting point, vapor-phase transport can lead to particle growth. Moreover, because the growth time to a given radius goes as $r^{4}$, there is a natural mechanism to (effectively) stop particle growth upon reaching the requisite 300-micron size. Barnes et al. (2008) [9] calculated that such growth might take $10^{4}$ to $10^{8}$ years for candidate organics under Titan conditions.

A similar process may be at work on Earth in the formation of snow dunes in the Antarctic [31]. Those transverse dunes have particles that grow using vapor-phase recrystallization, which is somewhat akin to sintering of organics on Titan. Because the ice is near its melting point, however, the sintering process in snow dunes is so effective that the ice eventually grows crystal sizes up to $1 \mathrm{~cm}$ (!) in places [31], ultimately rendering those particles too large for saltation. Hence a potential problem with sintering is that particles should eventually grow beyond saltatable size, immobilizing any dunes that require active saltation (which the Antarctic dunes evidently do not). Given that the continued presence of sand-free interdunes implies that Titan's dunes are presently active [9], sintering would require that the age of Titan's sands be precisely that required to grow particles to but not beyond saltatable size. Alternatively, sintering could be countered by physical abrasion or erosion to keep particles in a saltatable size range.

The bottom-up sintering hypothesis allows for testing. If it is correct, then the composition of the dune sands ought to directly mirror that of the haze itself with little modification.

With regard to sand sources as I discuss in the following Section, the bottom-up approach allows for a single sand source (haze fallout) distributed across the entire globe. That source would yield sand fluxes proportional to the haze accumulation rate at each point. Thus no individual sand sources should be identifiable. As a corrolary, however, all of that sand needs to find its way down to the equatorial sand seas. This transport might be expected to manifest as barchan dunes marching from the pole toward the equator, where the sand that they transport would then be subsumed within the giant longitudinal dunefields. Because these barchan dunes should be of order 30-300 $\mathrm{m}$ in size, they would not be detectable by Cassini. Sand sheets could also serve as a means to deliver sand to the equator, however the mid-latitudes show a spectral signature that does not match that of the sand seas. Future missions, including airplanes [32], hot-air balloons [33], and highresolution space-borne imaging [34] would be capable of detecting and characterizing such barchans, should they exist.

\section{Flocculation}

With the discovery of Titan's hydrocarbon lakes and seas [35], we now suggest a possible bottom-up formation process that occurs subacqueously: flocculation. Flocculation is a process wherein suspended solids clump together due to turbulence within a body of 
liquid. When the liquid dries up, the clumps are left behind as flakes. Once dried, the flocculated clumps can be saltated by the wind to form dunes. This process forms sand in coastal sebkhas in Morocco on Earth.

The tholin haze particles that descend from the atmosphere are composed of a rich mix of compounds, including many refractory, high molecular weight and insoluble compounds such as polycyclic aromatic hydrocarbons (PAHs) and nitrogen-substituted PAHs (PANHs), as well as low-molecular-weight compounds such as butane and acetonitrile. Suspended in the seas, these particles may be 'washed' clean of these labile compounds (which go into solution, and perhaps are eventually deposited as evaporites), but the small particles may clump together by Van der Waals forces, forming larger aggregates. They may sinter slowly into rounder particles, and/or be cemented together by evaporite material when the seas dry up.

This mechanism allows the sand to be made from insoluble material, which is favorable in that the most abundant evaporite candidate materials are rather soft (Lorenz et al.: Organic Ices at Cryogenic Temperatures: First Steps towards a 'Mohs scale'for Titan Geological Materials, submitted) and may therefore be ill-suited to large-scale transport by saltation. Because Van der Waals forces do not depend on the polarity of the molecules involved, they should be effective in Titan's seas where water-like hydrogen bonds do not work.

There is evidence for PAHs and PANHs in infrared spectroscopy of Titan's haze [36], as well as direct detection by mass spectroscopy of anthracene (a PAH) and macromolecules and molecular clusters with atomic masses as high as 40,000 [37].

A challenge to the flocculation model (shared by the evaporite mechanism suggested below) is that the sand originates with the lakes and seas at high latitude, whereas it evidently accumulates near the equator. This requires not only a horizontal journey of over $3000 \mathrm{~km}$, but also a vertical ascent of almost $1 \mathrm{~km}$. Upward movement clearly cannot be accomplished fluvially, so aeolian transport must be responsible. Transport by saltation over such distances might be expected to lead to rounding and fining of particles. The fact that material can still be saltated into dunes at the equator after this journey may suggest that fining does not occur, perhaps because individual saltation jumps are rather short [23] and nonenergetic. Evaporite-derived and flocculated sands would not have a much shorter journey if they originated in the putative Tui Regio and Hotei Regio paleo-sea basins $[38,39]$ instead. While the lack of longitudinal duneforms next to the north polar lakes and seas themselves could be explained away by transport via sand sheets instead of dunes, no "dark brown" dune spectral material has been seen poleward of $40^{\circ}$ latitude.

\section{Top-down}

The other possibility for the production of sand is the top-down approach, wherein sand particles are eroded from larger rocks. Earth's dune sands are produced in this way. On Titan, though, there is the additional wrinkle that those larger rocks must be generated first, since the bedrock appears to be dominated by water ice and not the organic material more typical of the dunes.

\section{Lithification and erosion}

One possibility is to imagine that Titan's haze-derived organic solids get buried and subsequently lithify. Lithification could also potentially occur via cementation by evaporation 
of liquid from pore space. Rain may carry haze particles from their distribution across the surface through channels into either lakes or deltas, where the sediment load gets dumped. Over time those sediments could build to considerable thickness. Then overburden pressure could close up the pore space within the sediment and indurate it into less friable material. Such a process would build a rock that might resemble terrestrial mudstone or slate.

This complex process for production of lithified organic rock only gets us to the starting point for Earth-like sand production. In the Titan case, that buried organic rock would then need to be exhumed and eroded down to produce sand-sized particles. The efficacy of fluvial erosion, at least, is well-established on Titan given its channels and riverbeds [40].

This scenario necessitates that complex sedimentary structure exist beneath Titan's visible surface, and that Titan has had considerable geologic time to both produce such structures and then later erode them. Aerial vehicles might be able to directly observe this kind of structure in the 100s-of-meters-high walls [41] of canyons excavated by Titan's methane rivers.

Like direct sintering, lithification followed by erosion would generate sand compositions similar to that of the haze. Different from sintering, however, erosion of the organic rock (and thus the production of sand grains) should take place in distinct and possibly isolated locales. Thus there would be discrete sand sources that might be able to be found by Cassini. Such sources might be characterized by exposure of organic rock units with spectra resembling that of the dunes.

Alternately if haze-derived organic materials make up a large fraction of Titan's crust (as they would if karstic processes drive lake basin formation) then erosion due to small channels and gullies could produce sand without discrete sources.

\section{Evaporite (white sands)}

An alternative, new top-down scenario evokes the formation mechanism for the dunes at White Sands, New Mexico, USA. The distinctive color that gives these dunes their name comes from their composition. The White Sands dune particles are made of gypsum, not silica. The gypsum was deposited as evaporite at the bottom of a nearby lake during the wetter Pleistocene epoch 11,700 to 2,588,000 years ago. After the lake dried up, aeolean erosion of the evapritic surface mobilized gypsum particles. Downwind of the lake, the particles have organized themselves into a dunefield over the past $\sim 15000$ years (Figure 2).

The evaporitic source hypothesis also has testable predictions. The composition of the dune sands should not be the same as the haze, but should rather be made up of just that component of the haze that dissolves in methane and forms the evaporites.

Under this scenario the dune sands would be produced from discrete, known sources: evaporitic lakebeds. Since they are already known, we can evaluate the evaporites as possible sources for the sand by comparing their spectra. The comparison is negative - while the evaporites are the brightest solids on Titan's surface, the dunes are the darkest. Both, however, show ice-free signatures that could be organic in nature.

Sands on Earth are known to change spectral character (i.e., color) with exposure under different conditions. In the Namib sand sea, for instance, the sand is paler near the coast and becomes progressively redder further inland. Although this variation was initially 


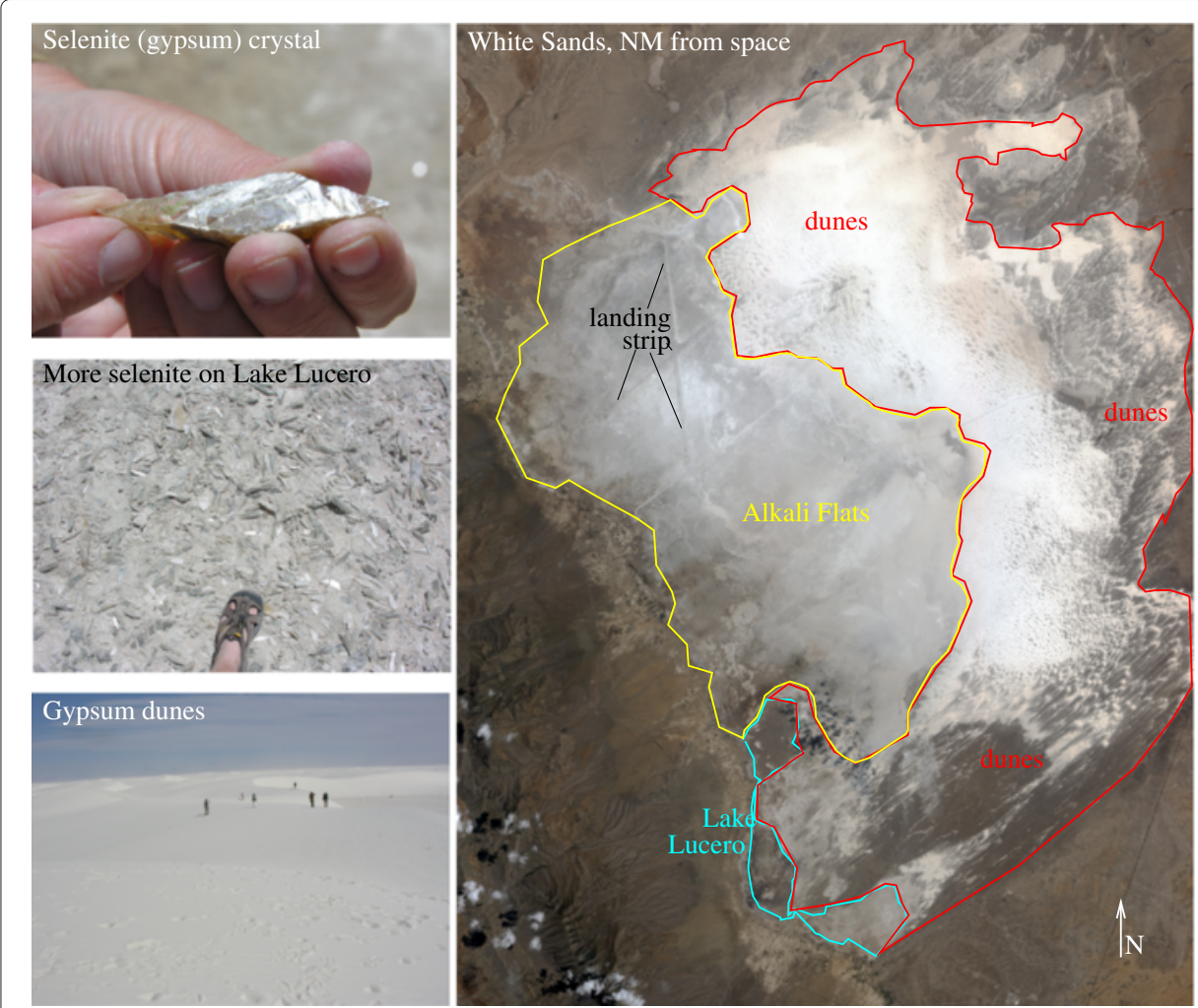

Figure 2 White sands. Views of White Sands, New Mexico, USA. At right is an orbital view from EO-1 showing White Sands and vicinity. The Alkali Flats area and Lake Lucero are the sources of the white sand. Both are paved with selenite crystals (upper-left and left) - evaporitic remains of Pleistocene Lake Otero. The gypsum blows ENE with the prevailing winds to produce dunes downwind from the lakebed (lower-left), which take on barchan, barchanoid, transverse, and dome dune forms. Space Shuttle Columbia landed on the airstrip at the northwest end of the alkali flats (White Sands Space Harbor) on 1982 March 30 due to inclement weather at Edwards Air Force Base

attributed purely to the sands' age [42], current thinking is that the colors in the Namib may be driven by dune activity. According to Lancaster (1989; [43]), sands that saltate more often "give rise to paler colors through abrasion of coatings on grains and decreased opportunities for weathering".

It is possible that a similar optical maturation process for sand could operate on Titan, allowing evaporites to be the source of the dune sands. Processes that could do this might be chemical or physical. Chemical weathering of grains' surfaces could alter their exteriors, producing a rind. With a distinct chemical composition, that rind might then show a different, darker spectrum. Physical processes that could alter the sand's albedo include grain size growth and mechanical rounding. The spectra of granular materials depends strongly on the particle size: larger grains are more highly absorbing than small grains, all else being equal. Hence grain growth (maybe akin to sintering) could plausibly lead to dark sand grains originating from bright evaporites. A perhaps more likely scenario on these lines, though, regards the grains' surface roughness. Jagged-edged particles behave more like small-grained particles, with more reflective scatters per incident photon and shorter distances traveled within the particle where absorptions occur. Hence if the evaporites themselves are rough, any sand-sized particles that they produce could be rounded in transport, leading to decreases in their albedo. 
Such a maturation process might, however, act to maintain some compositional similarity to evaporitic material. As such it might still show the Hotei-Tui 4.92 micron absorption [18], albeit at a lower level. The present signal-to-noise ratio for VIMS observations of Titan's sand does not allow for this test, but atmospherically corrected data (e.g., from [44]), could, in the future, allow for such a test by enabling massive coaddition of dune pixels.

\section{Where?}

Each of the sand creation processes proposed in the previous section with the exception of sintering imply that production should occur in discrete geographical locations. To test whether discrete sources exist, we search the global VIMS Titan dataset for spectral signatures that might match that of the dune sands. If a discrete source were to exist outside of the sand seas themselves, it might be detectable using this method (though not necessarily so).

First we compile a map of Titan using VIMS best-resolution and best-viewing-condition data at each point. To correct for the significant atmospheric contributions, we employ the empirical correction developed by Le Mouèlic et al. (2012) [45] for the $1.08 \mu \mathrm{m}$, $1.28 \mu \mathrm{m}, 1.6 \mu \mathrm{m}, 2 \mu \mathrm{m}$, and $2.8 \mu \mathrm{m}$ windows, and we use a simple analytical singlescattering model from Vixie et al. (2014) (Vixie et al.: Two Temperate Lakes on Titan, in revision) to correct the $5 \mu \mathrm{m}$ window. We show the resulting map in Figure 3. For purposes of quantitative spectral intercomparison, we normalize the map within each band by subtracting the mean and dividing by the standard deviation.

To test for similarity between the dunes' spectra and that elsewhere, we assume a dune endmember spectrum as a 6-dimensional vector using the spectral windows from the corrected map. We coadd the spectra of a region within the sand sea Aztlan to take as our sand endmember spectrum.

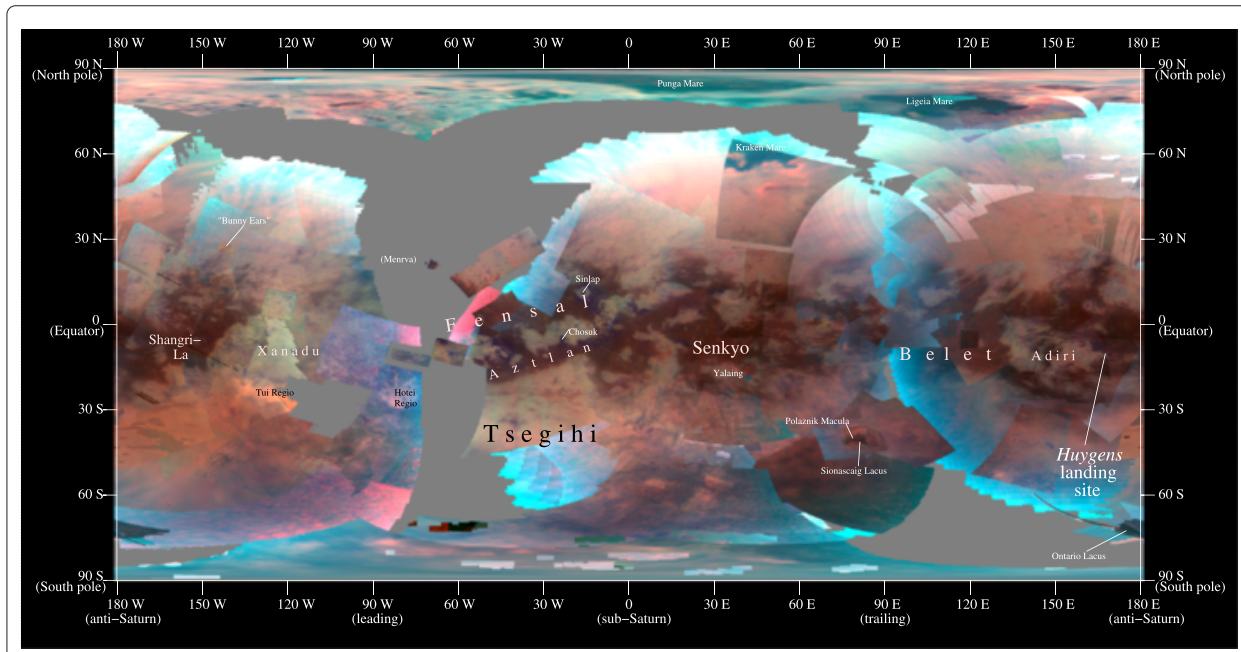

Figure 3 Global color mosaic. Global VIMS color mosaic of Titan. We used the empirical atmospheric correction by [45] for Titan's atmospheric windows at $1.08 \mu \mathrm{m}, 1.28 \mu \mathrm{m}, 1.6 \mu \mathrm{m}, 2 \mu \mathrm{m}$, and $2.8 \mu \mathrm{m}$, and a single-scattering atmospheric model from (Vixie et al.: Two Temperate Lakes on Titan, in revision) for $5 \mu \mathrm{m}$. The map uses the best views of each area, but we remove pixels with incidence, emission, or phase angles above $80^{\circ}$. Those removed pixels are grey in the map. The correction works best at longer wavelengths; hence some residual haze becomes prominent in blue given our color mapping of $\mathrm{R}=5 \mu \mathrm{m}, \mathrm{G}=2 \mu \mathrm{m}$, $\mathrm{B}=1.28 \mu \mathrm{m}$. The bright pink areas represent overcorrections of the $5-\mu \mathrm{m}$ window and are thus artifacts. 
We show the resulting map of distance in 6-dimensional spectral space between each point in Figure 4. Large distances appear bright in Figure 4, and small distances appear dark. Immediately you can see the primary restriction of dune material to Titan's equatorial regions $[2,3,12,46]$. Unfortunately the distance metric keys primarily off of broader albedo differences and not subtle spectral variation. Hence instances of the VIMS "dark blue" unit $[19,20,47]$, such as those around Sinlap crater [48], appear dark. They are good (though not perfect) matches to the dune material because they both have low albedos.

The dark matches for dune spectra span most longitudes around the equator [46]. The gap around $100^{\circ} \mathrm{E}$ longitude corresponds to an area with an imperfect atmospheric correction, as seen from the blue tinge in the map in Figure 3. A perfect correction would show that the dunes are continuous throughout the Belet sand sea. The other gap surrounds Xanadu at $110^{\circ} \mathrm{W}$. The east end of this gap in west Aztlan and around Menrva crater at $60^{\circ} \mathrm{W}$ is an artifact of VIMS' lack of coverage of the area at good viewing geometries. However the western end of this gap from $130^{\circ} \mathrm{W}$ to $100^{\circ} \mathrm{W}$ does represent a lack of dune coverage.

The only potentially useful match for dune material comes from the southern temperate area around Sionascaig Lacus (Vixie et al.: Two Temperate Lakes on Titan, in revision). As noted by Vixie et al. 2014 (Vixie et al.: Two Temperate Lakes on Titan, in revision), most of the dark alebedo feature Polaznik Macula to the northwest of the prospective lake Sionascaig Lacus resembles sedimentary lake deposits that could potentially be wetted. The spectra and 5-micron albedo at Polaznik resemble that of dune material. If Polaznik were a sand source region, such a source would potentially be consistent with three production models - lithification followed by erosion, flocculation, and evaporite - but inconsistent with sintering. Flocculation might, in fact, be most consistent with Polaznik as a sand source given Polaznik's dark surface albedo. Note, however, that there are no dunes visible in near-infrared imagery downwind of the Polaznik lakebed. Given the low

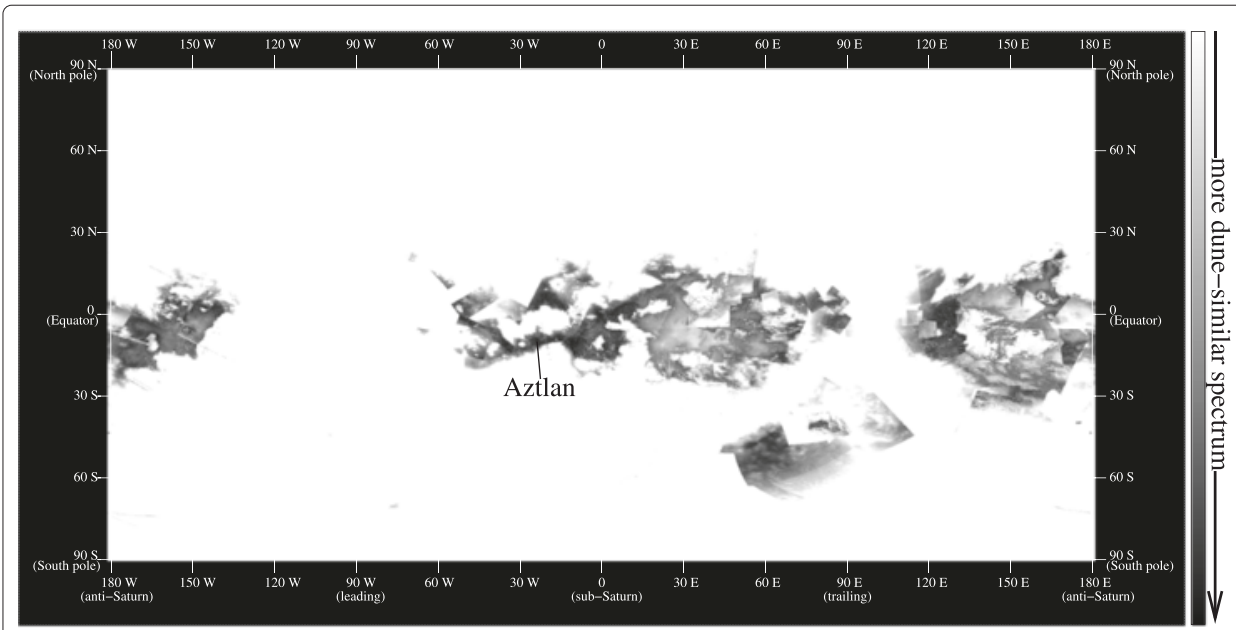

Figure 4 Dune spectral distance. Global spectral distance map. We show the distance in $\{1.08 \mu \mathrm{m}, 1.28 \mu \mathrm{m}$, $1.6 \mu \mathrm{m}, 2 \mu \mathrm{m}, 2.8 \mu \mathrm{m}, 5 \mu \mathrm{m}\}$ vector space from a pixel's atmospherically corrected and normalized albedo to the average value for the dunes in Aztlan. The base map is the empirically corrected mosaic from Figure 3. Due to systematic errors in the atmospheric correction, the map should still be considered in context with the observation geometry. Broadly, the distances map closely to albedo variations — the VIMS 'dark blue' spectral unit (which includes the Sinlap parabola and the Huygens Landing Site, for instance) shows a small distance (dark) from the sand spectrum despite its distinct spectral signature [19,20]. 
accuracy of the test that we have applied, however, the similarity could just be that of two low-albedo materials resembling each other more than brighter terrains.

Southwest of Polaznik and Sionascaig is another region of low spectral distance from Aztlan's dune material. This area shows several large $(\sim 100 \mathrm{~km})$ surface spectral units that nearly match the dune spectrum. However the sharp borders of the area in the distance map implicate viewing geomety and an imperfect atmospheric correction as a driver of the similarity. While by no means definitive, the spectral similarity of the region merits follow-up observations.

Interestingly, neither Ontario Lacus [49-54] nor Titan's north polar lakes and seas $[35,55,56]$ show a spectral match for Titan's dunes, despite similarly low albedos. Despite the potential lake sediments in Polaznik matching, no similar sediments associated with the north polar lakes and seas show a match in Figure 4. The seas' spectra differ from those of the dunes (for one, they are bluer due to specular reflections off of the seas illuminating atmospheric haze from below [57]), so the nonsimilarity could be real. It could also result from geometric effects on the atmospheric correction, which should be greatest near the poles which never receive low solar incidence angles.

While the analysis in this section remains preliminary, a more thorough comparison in the future using a map with more accurate surface albedos could yet shed light on potential sand source regions.

\section{When?}

The sand source search in the previous section works best if the dune sands themselves are young and still being produced today. That assumption may be incorrect. In this section we consider the idea that Titan's sand grains could be ancient, wherein they are now likely far from where they were produced and ongoing sand production could be slow or nonexistent.

Titan's dunes are longitudinal in form [15]. On Earth, longitudinal dunes represent the most mature style of organization in sand seas. In general, longitudinal dunefields take millions of years to develop on Earth and probably do on Titan as well. Therefore Titan's dunes cannot be as young as the 15,000-year-old White Sands.

The sands' geographic distribution also leads us to consider that Titan's sands might be ancient. In particular, unlike the young dunes at White Sands from Figure 2 that extend downwind in close proximity to their source, Titan's dunes extend globally. Titan's sand seas are located within $30^{\circ}$ of the equator and extend eastward from $80^{\circ} \mathrm{W}$ all the way around to $130^{\circ} \mathrm{W}$ (Figure 5). This equatorial gathering of sand would only match a production mechanism with discrete sand sources if either (1) those sources themselves concentrate near the equator, or if (2) the sands have been blown far from their source regions.

Furthermore, the interconnected nature of Titan's sand seas implies a possible global transport system that would require ancient sands. In Figure 5 we show that with a few possible exceptions (inside Adiri and east of Yalaing Terra), there are no isolated dunefields on Titan. Each instance of the dark brown spectral unit that represents dune sands has a connection to the global sand sea. Presumably, given the global west-to-east sand transport implied by the individual dune patterns [2], the connections from the west provide a source for sands. Connections to the east, then, represent a pathway for sands to exit each region. 


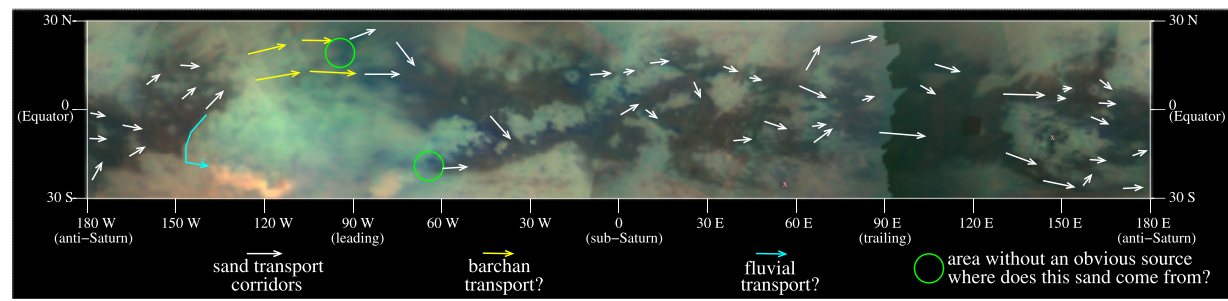

Figure 5 Sand transport map. Notional sand transport map with VIMS R $=5 \mu \mathrm{m}, \mathrm{G}=2 \mu \mathrm{m}, \mathrm{B}=1.3 \mu \mathrm{m}$ of Titan's equatorial region in cylindrical projection. The annotations on the map show that each major sand sea or dune field has sand corridors from the west from which new sand can arrive and sand corridors to the east for it to exit. Two possible exceptions are indicated as pink 'x's: small dunefields within Adiri and some east of Yalaing Terra. The major obstacle to global sand transport then is Xanadu, for which we propose two possible mechanisms for the sand to bridge the gap (see text), fast-moving barchan dunes and fluvial sediment transport in river channels. These particular sand transport corridors are hypothetical, though consistent with both topography [59] and observed sand transport directions [3]

That a global transport system must move sand particles thousands of kilometers has implications for the sand's texture. Specifically, if the sands have come many thousands of kilometers, they should be expected to display heavily rounded shapes due to their many collisions in transit. The particles themselves would need to be resistant to continued breakdown as they saltate. These predictions could be tested by a future dune lander with a hand lens imager and the capability to physically manipulate the sands.

The glaring broken link in the global equator-girdling chain of sand seas is Xanadu. Our suggestion of a single, integrated, global sand sea for Titan would require a mechanism for sand to move through Xanadu.

At Xanadu's north end, we suggest that sand transport could occur as chains of small, fast-moving Barchan dunes instead of the longitudinal dunes that we see elsewhere. The longitudinal dunes peter out irregularly in northeastern Shangri-La (see the VIMS "Bunny Ears" in Figure 6). Savage et al. (2014) said that the discontinuous dunes this far from the equator might result from restricted sand supply. That restricted sand supply could

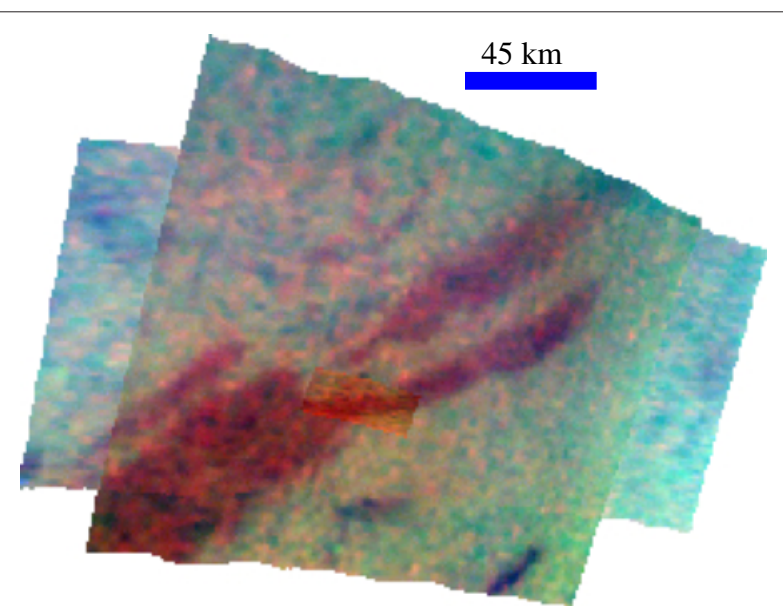

Figure 6 Northeast Shangri-La. The VIMS "Bunny Ears" centered at $27.5^{\circ} \mathrm{N} 141.8^{\circ} \mathrm{W}$ in northeast Shangri-La. This VIMS R $=5 \mu \mathrm{m}, \mathrm{G}=2 \mu \mathrm{m}, \mathrm{B}=1.3 \mu \mathrm{m}$ contrast-enhanced image from the Tb flyby (2004 December 13) shows an area where the dunes start to peter out with no obvious topographic control at the northeast end of Shangri-La, north of Xanadu. Could the sand be organizing itself into fast-moving Barchan chains instead of longitudinal forms to transport the sand eastward from here?. 
in this particular case result from the removal of sediments eastward. Farther from the equator, and particularly up north of $25^{\circ} \mathrm{N}$ where the "Bunny Ears" are, the wind patterns significantly differ from those near the equator, facilitating a different dune form. Thus the sand from northeast Shangri-La might pass across Xanadu from west to east as Barchan dunes. Because Barchans are typically small (10-100m), they would not yet have been detected by either VIMS or RADAR (though Lucas et al., 2014 [8], claims that larger megabarchans may have been detected in the RADAR data). Furthermore, Barchan transport across northern Xanadu would explain the dunes' re-emergence on the other side of Xanadu, west of Menrva crater. Without either transport across northern Xanadu or a new sand source in northeastern Xanadu, the start of sand seas west of Menrva would be unexplained.

At Xanadu's western border, the dunes stop abruptly (Figure 7, [58]). One idea is that a "great wall" of mountains holds back the sand at the western edge of Xanadu. Here, however, we suggest that the sharp edge of the dunes at the end of western Xanadu more probably results from a river channel. Xanadu's western border does not show a strong topographic signature [59]. Mountains much shorter than the atmospheric boundary layer height [16], as Titan's are, cannot stop sand dunes entirely. Instead, mountains deflect surrounding dune forms [3] around them, or cause the dunes to build up in height on the upwind side of the mountain until the sand overtops the obstacle.

Rivers, on the other hand, can stop a sand sea in its tracks. As an example, we show in Figures 8 and 9 images of the Kuiseb river in Namibia stopping the mighty Namib Sand Sea and forming its northern boundary. Even though the Kuiseb river flows only a few tens of days per year on average, no sand penetrates the channel to continue the sand sea on the other side. While the presence of vegetation on the banks of the Kuiseb river may play some role in sand transport through the channel, when translating to Titan the biological difference (plants vs. no plants) is likely less important than the geological differences (channel width and style, fluid flux and speed, and liquid/solid density ratio). The contrast between the desert landscape on each side of the riverbed is stark (Figure 9).

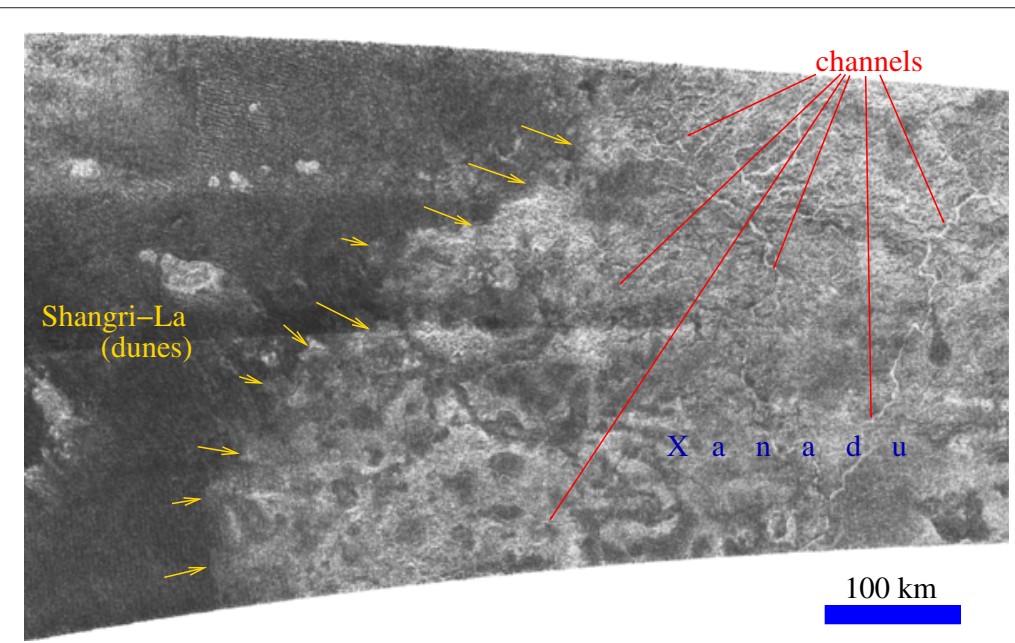

Figure 7 Western border of Xanadu. Cassini RADAR view of the western border of Xanadu, where the dunes from Shangri-La stop abruptly (yellow arrows). The interior of Xanadu has complex topography, but on average the terrain elevation within Xanadu is lower than it is in the sand seas [59]. Xanadu is also riven with river channels $[58,60,61]$. 


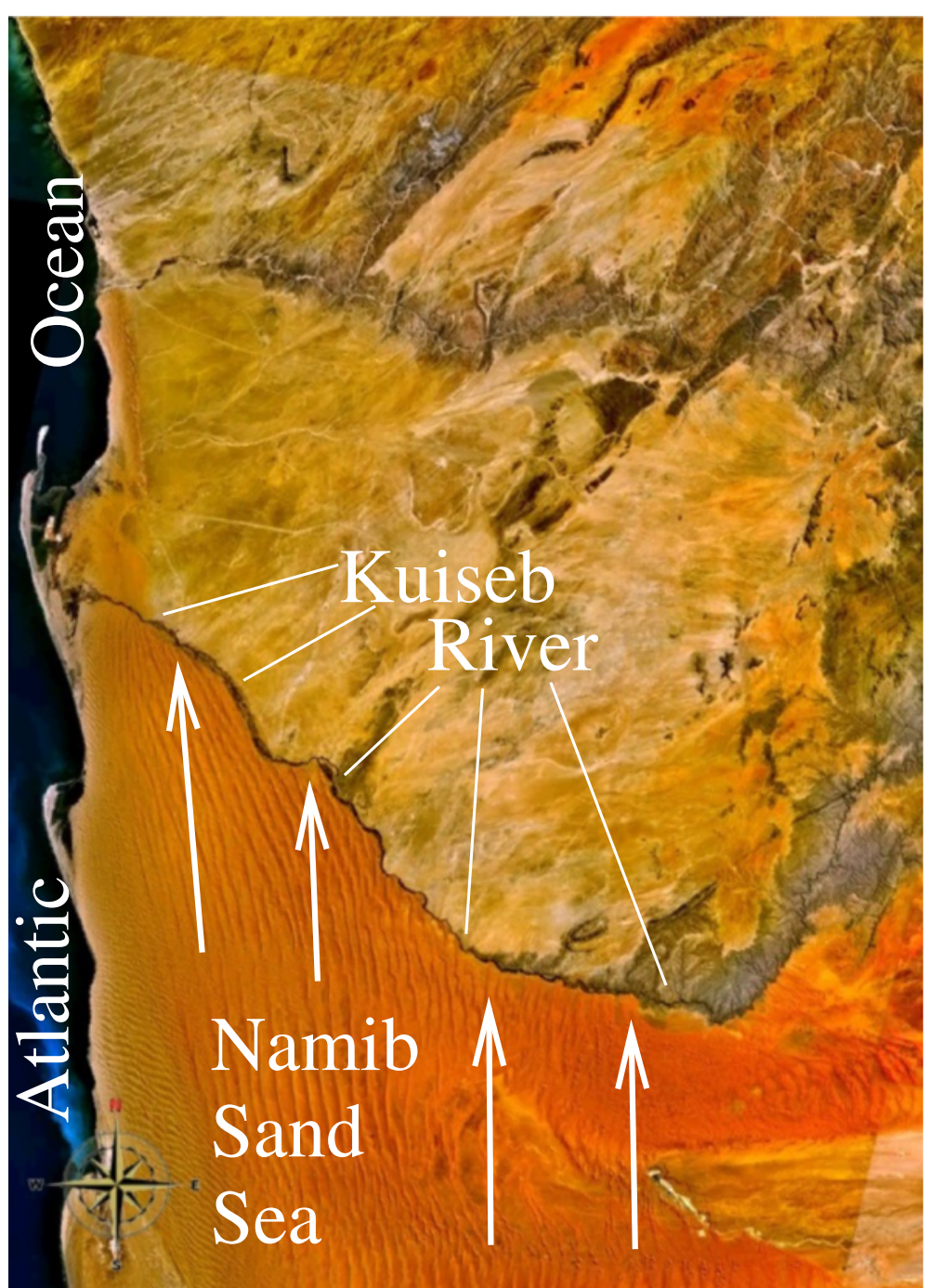

Figure 8 Namib sand sea and Kuiseb river from space. This Figure shows that the transient Kuiseb river forms the northern border of the mighty Namib Sand Sea in southwest Africa. Credit: earthobservatory. nasa.gov.

The sediments get washed downstream to the Atlantic Ocean instead of continuing past the fluvial obstacle.

The sharp border between the dunes and Xanadu shown in Figure 7 could be similarly defined by a transient riverbed. If such a river channel were the same size as the Kuiseb, it would be less than one RADAR pixel across and would thus be difficult to detect. Looking at the RADAR view in Figure 7, we see that although numorous large channels cross western Xanadu [58,60-63], none are identifiable directly at the dune/Xanadu interface.

Xanadu's channels flow southward, toward the empty basin of Tui Regio which has been suggested to be the site of a former hydrocarbon sea $[38,39,64]$. Hence when the channels of Xanadu fill, they may carry dune sands downhill into Tui Regio. Tui's spectral signature does not match that of the dunes, though, so sands deposited there would need to be either buried or 'rejouvenated' into high albedos by some process - washing, smoothing, or dissolution and reprecipitation might be candidate rejouvenation processes that could do the job. Where the sands travel from there is unclear. If they either 


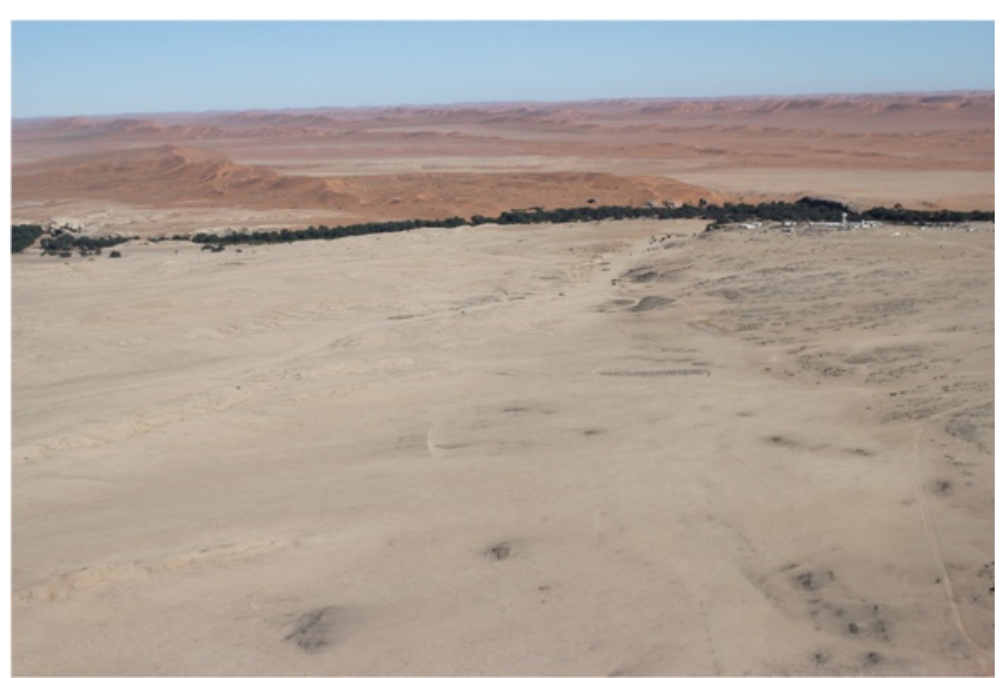

Figure 9 Namib sand sea and Kuiseb river from the Air. Kuiseb River stopping the dunes, as seen from the air Here we show that the longitudinal dunes of the Namib Sand Sea (visible as red-orange near the horizon to the south) do not continue past the Kuiseb river despite sand transport in the south-to-north direction. The dark material is vegetation that lives in the channel bottom even though the river flows only a few tens of days per year on average. The nearfield desert north of the riverbed is devoid of sand cover. The Gobabeb Desert Research Station is visible at the right, near the river.

move eastward via Barchan chains (as for northern Xanadu) or dissolve and reprecipiate (if the sand particles form from evaporite in the first place), then they could form the source that feeds western Aztlan.

A remaining question would then be: why do channels transport sand in Xanadu but nowhere else? With the possible exception of one tiny channel within dunes reported by Lopes et al. (2010) [65], channels do not appear numerous within the sand seas themselves. Maybe it rains more or more often in Xanadu than elsewhere, as has been suggested by ground-based observations [66], or maybe the catchment for Xanadu's channels are larger than those in smaller regions like that feeding Chosuk Planitia [67].

\section{Why?}

Titan's extensive sand seas cover more than $20 \%$ of its area [46] and serve as a surface sink for chemically-evolved hydrocarbon products of methane photolysis. The sand may also represent a long-term tracer for Titan's ancient sediments, like buried sandstones do on Earth. Hence understanding the origin and evolution of Titan's sands represents an important outstanding question raised by the Cassini mission.

Knowledge of the composition of the sands would provide a critical clue as to how the individual sand particles get made. If the sand composition matches that of the haze, then it could be produced by sintering or by burial and erosion. If the sand composition matches that of the evaporite, however, then an evaporitic origin like White Sands, USA would be favored. Conversely, a sand particle composition made primarily from insoluble compounds would be consistent with flocculation.

Laboratory experimentation to demonstrate the flocculation of PAH microparticles in a nonpolar solvent, and their adhesion by evaporite and/or sintering would be useful. Evaluation of the mechanical hardness and cohesion of various candidate materials such as PAHs and evaporites would also be useful. 
Given the lack of evident discrete sand sources and the generally interconnected nature of the equatorial sand seas, we suggest that Titan's sands may in fact represent a single near-global sand sea. The implications of such a single, interconnected reservoir would be that sand fluxes between the individual dunefields must allow them to be in equilibrium, and that the seas should be globally well-mixed.

A single global sand sea would require some mechanism by which the sands could bypass Xanadu from west to east, given that Xanadu represents a break in the longitudinal sand distribution. We suggest that the sands may bypass Xanadu on the north as chains of Barchan dunes, and on the south by fluvial transport downhill into Tui Regio. Both of these scenarios could be tested by future high-resolution imagery from either orbital $[34,68]$ or airborne $[32,69-73]$ mission platforms.

If Titan's net sand transport speed were to be similar to those in Earth's large longitudinal dune seas $(\sim 1 \mathrm{~m} / \mathrm{yr})$, then if would take $16 \mathrm{Myr}$ for particles to circulate around the globe once. Even if Titan's sand moves more slowly than that on the Earth, there has been plenty of time therefore to create the global sand sea. This timescale could also represent a lower limit on the age of the sand seas in general.

Given their areal extent, chemical significance, and sedimentary dynamics, Titan's sand dunes should be a prime target for future missions to Titan. Their possibility as a landing site [68] would allow direct observations of nature of the sand particles, their chemistry, and the atmospheric conditions in which they form. A Titan dune lander would need to take care to make sure that it landed at a location from which sand sampling would be possible - sand free interdunes cover $60 \%$ of Earth's Namib sand sea. Therefore some type of platform mobility might be necessary to ensure sampling of the dunes. While rovers would work, helicopters [74] or a hopper using compressed Titan air might be better choices for surface mobility in Titan's particular environment. Regardless of the platform, Titan's dunes will be a priority target for future exploration.

\section{Endnotes}

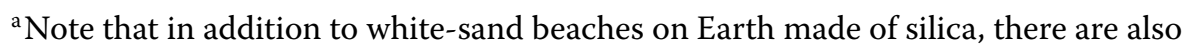
pink-sand beaches made of broken-up coral and shells, black-sand beaches made of basalt, and green-sand beaches made of olivine. This list serves to dispel the notion that sand need necessarily be made of silica.

Competing interests

The authors declare that they have no competing interests.

\section{Authors' contributions}

All authors were part of the 2013 Namib field study from which the ideas in this work were generated. JWB executed the spectral distance analysis. JWB wrote the text with significant contributions from RDL and JR. All authors read and approved the final manuscript.

\section{Acknowledgements}

The authors thank Shannon MacKenzie for editing assistance and Catherine Neish for a constructive review. JWB acknowledges support from NASA Outer Planets Research Program grant NNX09AP34G and from NASA Cassini Data Analysis and Participating Scientist Program grant NNX12AC28G.

\footnotetext{
Author details

${ }^{1}$ Department of Physics, University of Idaho, Moscow, Idaho, 83844-0903 USA. ${ }^{2}$ Applied Physics Laboratory, Johns Hopkins University, Laurel, MD 20723 USA. ${ }^{3}$ Department of Geology, Brigham Young University, Provo, UT 84602 USA

${ }^{4}$ Department of Astronomy, Cornell University, Ithaca, NY, 14853 USA.
} 


\section{References}

1. Lorenz RD, Wall S, Radebaugh J, Boubin G, Reffet E, Janssen M, et al. The Sand Seas of Titan: Cassini RADAR Observations of Longitudinal Dunes. Science. 2006;312:724-7.

2. Radebaugh J, Lorenz RD, Lunine JI, Wall SD, Boubin G, Reffet E, et al. Dunes on Titan observed by Cassini Radar. Icarus. 2008;194:690-703.

3. Lorenz RD, Radebaugh J. Global pattern of Titan's dunes: Radar survey from the Cassini prime mission. Geophys Res Lett. 2009;36:L3202.

4. Tokano T. Dune-forming winds on Titan and the influence of topography. Icarus. 2008:194:243-62.

5. Mitchell JL, Pierrehumbert RT, Frierson DM, Caballero R. The impact of methane thermodynamics on seasonal convection and circulation in a model Titan atmosphere. Icarus. 2009:203:250-64.

6. Friedson AJ, West RA, Wilson EH, Oyafuso F, Orton GS. A global climate model of Titan's atmosphere and surface. Planetary Space Sci. 2009;57(14\&15):1931-49.

7. Tokano T. Relevance of fast westerlies at equinox for the eastward elongation of Titan's dunes. Aeolian Res. 2010;2 $113-27$.

8. Lucas A, Rodriguez S, Narteau C, Charnay B, Pont SC, Tokano T, et al. Growth mechanisms and dune orientation on Titan. Geophys Res Lett. 2014;41:6093-100.

9. Barnes JW, Brown RH, Soderblom L, Sotin C, Le Mouè S, Rodriguez S, et al. Spectroscopy, morphometry, and photoclinometry of Titan's dunefields from Cassini/NIMS. Icarus. 2008;195:400-14. doi:10.1016/j.icarus.2007.12.006.

10. Neish CD, Lorenz RD, Kirk RL, Wye LC. Radarclinometry of the sand seas of Africa's Namibia and Saturn's moon Titan. Icarus. 2010;208:385-94.

11. Mastrogiuseppe M, Poggiali V, Seu R, Martufi R, Notarnicola C. Titan dune heights retrieval by using Cassini Radar Altimeter. Icarus. 2014;230:191-7.

12. Le Gall A, Janssen MA, Wye LC, Hayes AG, Radebaugh J, Savage C, et al. Cassini SAR, radiometry, scatterometry and altimetry observations of Titan's dune fields. Icarus. 2011;213:608-24.

13. Le Gall A, Hayes AG, Ewing R, Janssen MA, Radebaugh J, et al. Latitudinal and altitudinal controls of Titan's dune field morphometry. Icarus. 2012;217:231-42.

14. Ewing RC, Hayes AG, Lucas A. Sand dune patterns on Titan controlled by long-term climate cycles. Nat Geosci. 2015;8:15-9.

15. Radebaugh J, Lorenz R, Farr T, Paillou P, Savage C, Spencer C. Linear dunes on Titan and earth: Initial remote sensing comparisons. Geomorphology. 2010;121(1-2):122-32. [Planetary Dune Systems].

16. Lorenz RD, Claudin P, Andreotti B, Radebaugh J, Tokano T. A 3 km atmospheric boundary layer on Titan indicated by dune spacing and Huygens data. Icarus. 2010;205:719-21.

17. McCord TB, Hansen GB, Buratti BJ, Clark RN, Cruikshank DP, D'Aversa E, et al. Composition of Titan's surface from Cassini VIMS. Planet Space Sci. 2006;54:1524-39.

18. McCord TB, Hayne P, Combe JP, Hansen GB, Barnes JW, Rodriguez S, et al. Titan's surface: Search for spectral diversity and composition using the Cassini VIMS investigation. Icarus. 2008;194:212-42.

19. Soderblom LA, Kirk RL, Lunine Jl, Anderson JA, Baines KH, Barnes JW author=et al title=Correlations between Cassini VIMS spectra and RADAR SAR images: Implications for Titan's surface composition and the character of the Huygens Probe Landing Site. Planet Space Sci.. 2007;55:2025-36.

20. Barnes JW, Brown RH, Soderblom L, Buratti BJ, Sotin C, Rodriguez S, et al. Global-scale surface spectral variations on Titan seen from Cassini/VIMS. Icarus. 2007;186:242-58.

21. Janssen MA, Lorenz RD, West R, Paganelli F, Lopes RM, Kirk RL, et al. Titan's surface at 2.2-cm wavelength imaged by the Cassini RADAR radiometer: Calibration and first results. Icarus. 2009;200:222-39.

22. Clark RN, Curchin JM, Barnes JW, Jaumann R, Soderblom L, Cruikshank DP, et al. Detection and mapping of hydrocarbon deposits on Titan. J Geophys Res (Planets). 2010;115(E14):10005.

23. Lorenz RD. Physics of saltation and sand transport on Titan. A brief review. Icarus. 2014;230:162-7.

24. Burr DM, Bridges NT, Marshall JR, Smith JK, White BR, Emery JP. Higher-than-predicted saltation threshold wind speeds on Titan. Nature. 2015;517:60-3.

25. Lorenz R, Zimbelman J. Sand. In Dune Worlds. Springer Berlin Heidelberg: Springer Praxis Books; 2014, pp. 17-25.

26. Grotzinger J, Hayes A, Lamb M, McLennan S. Sedimentary Processes on Earth, Mars, Titan, and Venus In: Mackwell SJ, Simon M, Amy A, Harder JW, Bullock MA, editors. Comp Climatology Terrestrial Planets. Tucson: University of Arizona Press; 2014. 439-472.

27. Lorenz RD, Lunine Jl, Grier JA, Fisher MA. Prediction of aeolian features on planets: Application to Titan paleoclimatology. J Geophys Res. 1995;100:26377-86.

28. Lorenz R, Mitton J. Lifting Titan's veil: exploring the giant moon of Saturn. Cambridge, UK: Cambridge University Press; 2002

29. Waite J, Young D, Westlake J, Lunine J, McKay C, Lewis W. High-altitude production of Titan's aerosols. In: Titan from Cassini-Huygens. Dordrecht Heidelberg London, New York: Springer; 2010. p. 201-214.

30. Tomasko MG, Doose L, Engel S, Dafoe LE, West R, Lemmon M, et al. A model of Titan's aerosols based on measurements made inside the atmosphere. Planet Space Sci. 2008;56:669-707.

31. Fahnestock MA, Scambos TA, Shuman CA, Arthern RJ, Winebrenner DP, Kwok R. Snow megadune fields on the East Antarctic Plateau: Extreme atmosphere-ice interaction. Geophys Res Lett. 2000;27(22):3719-22.

32. Barnes JW, Lemke L, Foch R, McKay CP, Beyer RA, Radebaugh J, et al. AVIATR — Aerial Vehicle for In-situ and Airborne Titan Reconnaissance. A Titan airplane mission concept. Exp Astronomy. 2012;33:55-127.

33. Lorenz RD. Linear theory of optimum hot air balloon performance - application to Titan. Aeronautical J. 2008;112(1132):353-5.

34. Sotin C, Altwegg K, Brown RH, Hand K, Soderblom J, JET Team. JET: A Journey To Enceladus And Titan. In: AAS/Division for Planetary Sciences Meeting Abstracts \#42, Volume 42 of AAS/Division for Planetary Sciences Meeting Abstracts; Bulletin of the American Astronomical Society 2010. \#49.31.

35. Stofan ER, Elachi C, Lunine Jl, Lorenz RD, Stiles B, Mitchell KL, et al. The lakes of Titan. Nature. 2007;445:61-4. 
36. Sebree JA, Trainer MG, Loeffler MJ, Anderson CM. Titan aerosol analog absorption features produced from aromatics in the far infrared. Icarus. 2014;236:146-52.

37. Waite JH, Young DT, Cravens TE, Coates AJ, Crary FJ, Magee B, et al. The Process of Tholin Formation in Titan's Upper Atmosphere. Science. 2007;316:870.

38. Moore JM. Howard AD. Are the basins of Titan's Hotei Regio and Tui Regio sites of former low latitude seas? Geophys Res Lett. 2010;37:L22205.

39. Barnes JW, Bow J, Schwartz J, Brown RH, Soderblom JM, Hayes AG, et al. Organic sedimentary deposits in Titan's dry lakebeds: Probable evaporite. Icarus. 2011;216:136-40.

40. Burr DM, Emery JP, Lorenz RD, Collins GC, Carling PA. Sediment transport by liquid surficial flow: Application to Titan. Icarus. 2006;181:235-42.

41. Lorenz RD, Lopes RM, Paganelli F, Lunine Jl, Kirk RL, Mitchell KL, et al. Fluvial channels on Titan: Initial Cassini RADAR observations. Planet Space Sci. 2008:56:1132-44.

42. Logan RF. The Central Namib Desert, South West Africa. 9, National Academies. Washington, DC: National Academy of Sciences; 1960.

43. Lancaster N. The Namib Sand Sea: dune forms, processes and sediments. Rotterdam, Netherlands: AA Balkema; 1989.

44. Titan's surface and atmosphere from Cassini/VIMS data with updated methane opacity. Icarus. 2013;226:470-486.

45. Le Mouélic S, Cornet T, Rodriguez S, Sotin C, Barnes JW, Baines KH, et al. Global mapping of Titan's surface using an empirical processing method for the atmospheric and photometric correction of Cassini/VIMS images. Planet Space Sci. 2012;73:178-90.

46. Rodriguez S, Garcia A, Lucas A, Appéré T, Le Gall A, Reffet E, et al. Global mapping and characterization of Titan's dune fields with Cassini: Correlation between RADAR and VIMS observations. Icarus. 2014;230:168-79.

47. Rodriguez S, Le Mouélic S, Sotin C, Clénet H, Clark RN, Buratti B, et al. Cassini/VIMS hyperspectral observations of the HUYGENS landing site on Titan. Planet Space Sci. 2006;54:1510-23.

48. Le Mouélic S, Paillou P, Janssen MA, Barnes JW, Rodriguez S, Sotin C, et al. Mapping and interpretation of Sinlap crater on Titan using Cassini VIMS and RADAR data. J Geophys Res (Planets). 2008;113:4003.

49. Brown RH, Soderblom LA, Soderblom JM, Clark RN, Jaumann R, Barnes JW, et al. The identification of liquid ethane in Titan's Ontario Lacus. Nature. 2008;454:607-10.

50. Barnes JW, Brown RH, Soderblom JM, Soderblom LA, Jaumann R, Jackson B, et al. Shoreline features of Titan's Ontario Lacus from Cassini/VIMS observations. Icarus. 2009;201:217-25.

51. Wall S, Hayes A, Bristow C, Lorenz R, Stofan E, Lunine J, et al. Geophys Res Lett. 2010;37:L5202.

52. Lorenz RD, Jackson B, Hayes A. Planet Space Sci. 2010;58:724-31.

53. Turtle EP, Perry JE, Hayes AG, McEwen AS. Shoreline retreat at Titan's Ontario Lacus and Arrakis Planitia from Cassini Imaging Science Subsystem observations. Icarus. 2011;212:957-9.

54. Cornet T, Bourgeois O, Le Mouélic S, Rodriguez S, Lopez Gonzalez T, Sotin C, et al. Geomorphological significance of Ontario Lacus on Titan: Integrated interpretation of Cassini VIMS, ISS and RADAR data and comparison with the Etosha Pan (Namibia). Icarus. 2012;218:788-806.

55. Hayes AG, Aharonson O, Lunine Jl, Kirk RL, Zebker HA, Wye LC, et al. Transient surface liquid in Titan's polar regions from Cassini. Icarus. 2011;211:655-71.

56. Sotin C, Lawrence KJ, Reinhardt B, Barnes JW, Brown RH, Hayes AG, et al. Observations of Titan's Northern lakes at $5 \mu \mathrm{m}$ : Implications for the organic cycle and geology. Icarus. 2012;221:768-86.

57. Barnes JW, Clark RN, Sotin C, Ádámkovics M, Appéré T, Rodriguez S, et al. A Transmission Spectrum of Titan's North Polar Atmosphere from a Specular Reflection of the Sun. apJ. 2013;777:161.

58. Radebaugh J, Lorenz RD, Wall SD, Kirk RL, Wood CA, Lunine Jl, et al. Regional geomorphology and history of Titan's Xanadu province. Icarus. 2011;211:672-85.

59. Lorenz RD, Stiles BW, Aharonson O, Lucas A, Hayes AG, Kirk RL, et al. A global topographic map of Titan. Icarus. 2013;225:367-77.

60. Burr DM, Jacobsen RE, Roth DL, Phillips CB, Mitchell KL, Viola D. Fluvial network analysis on Titan: Evidence for subsurface structures and west-to-east wind flow, southwestern Xanadu. Geophys Res Lett. 2009;36(22):

61. Langhans MH, Jaumann R, Stephan K, Brown RH, Buratti BJ, Clark RN, et al. Titan's fluvial valleys: Morphology, distribution, and spectral properties. Planet Space Sci. 2012;60:34-51.

62. Langhans M, Lunine Jl, Mitri G. Titan's Xanadu region: Geomorphology and formation scenario. Icarus. 2013;223(2): 796-803.

63. Burr DM, Drummond SA, Cartwright R, Black BA, Perron JT. Morphology of fluvial networks on Titan: Evidence for structural control. Icarus. 2013;226:742-59.

64. MacKenzie SM, Barnes JW, Sotin C, Soderblom JM, Mouélic SL, Rodriguez S, et al. Evidence of Titan's climate history from evaporite distribution. Icarus. 2014;243(0):191-207.

65. Lopes RMC, Stofan ER, Peckyno R, Radebaugh J, Mitchell KL, Mitri G, et al. Distribution and interplay of geologic processes on Titan from Cassini radar data. Icarus. 2010;205:540-558.

66. Ádámkovics M, de Pater I, Hartung M, Barnes JW. Evidence for condensed-phase methane enhancement over Xanadu on Titan. Planet Space Sci. 2009;57:1586-95.

67. Jaumann R, Brown RH, Stephan K, Barnes JW, Soderblom LA, Sotin C, et al. Fluvial erosion and post-erosional processes on Titan. Icarus. 2008;197:526-538.

68. Lorenz RD, Leary JC, Lockwood MK, Waite JH. Titan Explorer: A NASA Flagship Mission Concept In: El-Genk MS, editor. Space Technology and Applications International Forum-STAIF 2008, Volume 969 of American Institute of Physics Conference Series. Albuquerque, New Mexico; 2008. p. 380-387.

69. Hall JL, Lunine J, Sotin C, Reh K, Vargas A, Couzin P. Titan Aerial Explorer (TAE): Exploring Titan by Balloon". In: Proceedings of the Interplanetary Prove Workshop 8. Portsmouth, VA; 2011.

70. Sittler EC, Cooper JF, Mahaffey P, Esper J, Fairbrother D, Farley R, Pitman J, et al. Titan Orbiter with Aerorover Mission (TOAM). In: AAS/Division for Planetary Sciences Meeting Abstracts \#38, Volume 38 of Bulletin of the American Astronomical Society; 2006. p. 1300. 
71. Reh K, Manger T, Matson D, Coustenis A, Lunine J, Lebreton JP, et al. Titan Prebiotic Explorer (TiPEx) Mission Study Final Report. Pasadena, California: Jet Propulsion Laboratory; 2007.

72. Reh K, Manger T, Matson D, Coustenis A, Lunine J, Lebreton JP, et al. Titan Saturn System Mission Study 2008: Final Report, Task Order \#NMO710851. Pasadena, California: Jet Propulsion Laboratory; 2009.

73. Lunine J, Lorenz RD, Smith M, Beauchamp P, Beauchamp J, Hodyss R, et al. Titan Organics Explorer. NASA JPL Vision Mission Study. Pasadena, California: Jet Propulsion Laboratory; 2005.

74. Lorenz RD. Flight Power Scaling of Airplanes, Airships, and Helicopters: Application to Planetary Exploration. J Aircraft. 2001;38:208-14.

Submit your manuscript to a SpringerOpen ${ }^{\circ}$ journal and benefit from:

- Convenient online submission

- Rigorous peer review

- Immediate publication on acceptance

- Open access: articles freely available online

- High visibility within the field

- Retaining the copyright to your article

Submit your next manuscript at $\mathbf{s p r i n g e r o p e n . c o m ~}$ 